\title{
ANALISIS INFRASTRUKTUR SISTEM JARINGAN JALAN DAN PEJALAN KAKI PADA JL. LEGIAN, KUTA, BADUNG
}

\author{
A.A Gede Trisna Gamana Pratama \\ Program Studi Teknik Industri, Fakultas Teknik, Universitas Mahendradatta \\ J. Ken Arok No.12, Peguyangan, Denpasar, Bali 80115 \\ Email: trisnagamana@gmail.com
}

\begin{abstract}
Abstrak - Jalan Legian adalah jalan utama yang menghubungkan Kuta dengan Seminyak di Bali. Panjang ruas jalan ini sekitar 1,5 kilometer dengan dipenuhi berbagai toko, bar, hotel, dan club.Jalan Legian termasuk jalan lokal primer dengan lebar jalan sekitar 7,5 meter namun dengan volume kendaraan yang padat terutama di pagi hari dan sore hari mengakibatkan koridor ini rawan kemacetan.Tingkat kualitas sarana infrastruktur, dipengaruhi dari kualitas perencanaan dan pengawasan, salah satu indikator infrastruktur yang kurang baik khususnya jaringan jalan dan pejalan kaki adalah kemacetan. Penelitian ini menggunakan penelitian kualitatif deskriptif dengan pendekatan rasionalistik berdasarkan kenyataan dilapangan dengan data primer diperoleh dari hasil observasi, dokumentasi yang dipadukan dengan kebijakan Perda Kab Badung, RTRW Kab.Badung. Hasil penelitian menunjukkan masih banyaknya ditemukan ketidaktersediaan kelengkapan sarana ruang pejalan kaki dan alih fungi ruang pejalan kaki yang menyebabkan infrastruktur sistem jaringan koridor jalan ini rawan terjadi kemacetan.
\end{abstract}

Kata kunci :Sistem Jaringan Jalan, Ruang pejalan kaki, Jalan Legian

Abstract-Legian street is the main road that connects Kuta with Seminyak in Bali. The length of this road is around 1.5 kilometers filled with various shops, bars, hotels and clubs. Legian street is a primary local road with the width about 7.5 meters but with a solid volume of vehicles, especially in the morning and evening caused this corridor is prone to congestion. Quality level of infrastructure facilities, influenced by the quality of planning and supervision, one of the indicators of poor infrastructure, especially road and pedestrian networks, is congestion. This study uses descriptive qualitative research with a rationalistic approach based on reality in the field with primary data obtained from observations, documentation that is integrated with the policies of the Local Regulations of Badung Regency, RTRW Regency of Badung. The results of the study showed that there were still many incomplete pedestrian facilities and the transfer of pedestrian facilities which caused the road corridor network infrastructure to be prone to congestion.

Keywords : Road network system, Pedestrian, Legian street,

\section{PENDAHULUAN}

Jalan Legian adalah jalan utama yang menghubungkan Kuta dengan Seminyak di Bali. Panjang ruas jalan ini sekitar 1,5 kilometer dengan dipenuhi berbagai toko, bar, hotel, dan club. Karena banyaknya hiburan malam dan letaknya yang dekat dengan Pantai Kuta, membuat Jalan Legian menjadi salah satu tujuan wisata yang populer di antara wisatawan di Bali.

Penyebab kemacetan yang sering terjadi di koridor jalan Legian, Kuta adalah alih fungsi pejalan kaki. Pada koridor jalan Legian parkir on street dilarang hampir di seluruh koridor jalan, maka alih fungsi pejalan kaki kerap digunakan sebagai tempat parkir dan tempat memajang stand toko. Alih fungsi pejalan kaki tersebut mengakibatkan terganggunya kenyamanan pejalan kaki karena sebagian ruang pejalan kaki tidak digunakan sesuai fungsinya. Oleh sebab itu, menyebabkan keterbatasan ruang gerak pejalan kaki yang mengakibatkan pejalan kaki menggunakan jaringan jalan sebagai media berjalan sehingga membahayakan pejalan kaki dan meningkatkan kepadatan di jalan Legian. 
Kelengkapan sarana dan prasarana jaringan jalan merupakan suatu kelengkapan yang penting kaitannya dalam transportasi. Kelengkapan sarana dan prasarana jaringan jalan masih kurang optimal, terlihat dari minimnya titik-titik penyeberangan jalan sehingga banyak pengguna jalan yang menyeberang secara sembarangan sehingga menggangu arus lalu lintas. Kelengkapan saran dan prasarana pejalan kaki terdiri dari jalur hijau, lampu penerangan, tempat duduk, tempat sampah, pagar pengaman, marka dan perambuan. Pada koridor jalan Legian masih banyak ditemukan kelengkapan sarana dan prasarana pejalan kaki yaitu tempat sampah, tempat duduk dan lampu penerangan.

Kesesuaian standar dimensi dan bahan sarana infrastruktur jaringan jalan dan pejalan kaki yang berbeda di beberapa titik di koridor jalan Legian. Berdasarkan klasifikasi jalan, jalan Legian termasuk jalan lokal primer dengan lebar jalan sekitar 7,5 meter namun dengan volume kendaraan yang padat terutama di pagi hari dan sore hari mengakibatkan koridor ini rawan kemacetan. Kesesuaian standar dan bahan pejalan kaki yang berbeda di koridor jalan Legian antara sisi ruas kanan dan ruas kiri jalan. Bahan ruang pejalan kaki terbuat dari garnit tile dari hasil proyek beautifikasi Pemerintah Daerah Kabupaten Badung yang diharapkan mampu meningkatkan efek visual dan kenyamanan bagi pejalan kaki.

Menanggapi hal tersebut, maka diperlukan adanya Kebijakan Pembangunan Infrastruktur Sistem Jaringan Jalan dan Pejalan Kaki di Kabupaten Badung sehingga diharapkan mampu sebagai acuan ataupun penyempurna bagi pengampu pemerintah terkait kebijakan Peraturan Daerah di Kabupaten Badung sehingga mampu diaplikasikan dengan baik dalam praktisi di lingkungan masyarakat wilayah Kabupaten Badung.

\section{RUMUSAN MASALAH}

1. Bagaimanakah kondisi ekisting infrastruktur jaringan jalan dan pejalan kaki di Jalan Legian, Kuta Badung?

\section{Apakah faktor-faktor pengaruh}

ketidaksesuaian infrastruktur jaringan jalan dan pejalan kaki ?

\section{TUJUAN}

1.Mengidentifikasikondisi ekisting infrastruktur jaringan jalan dan pejalan kaki di Jalan Legian, Kuta Badung

2.Mengkajifaktor-faktor pengaruh ketidaksesuaian infrastruktur jaringan jalan dan pejalan kaki

\section{METODOLOGI PENELITIAN}

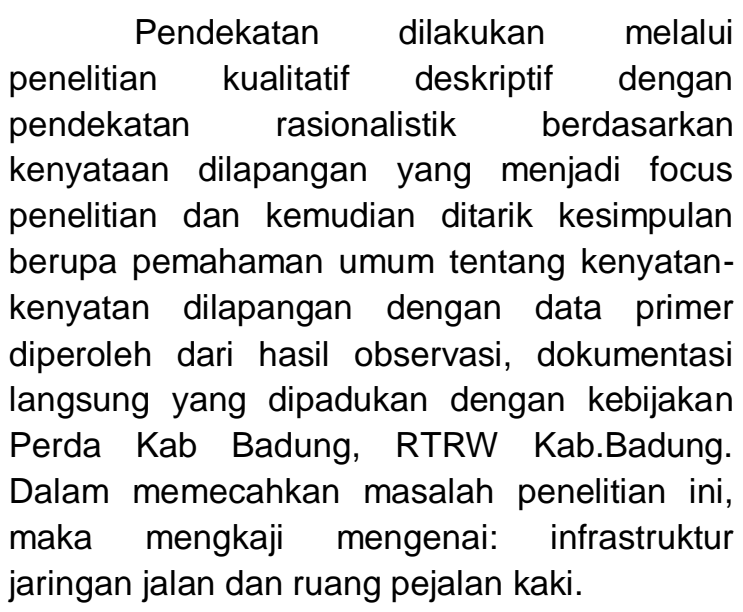

\section{PEMBAHASAN}

Pengertian Infrastruktur, menurut Grigg (1988) infrastruktur merupakan sistem fisik yang menyediakan transportasi, pengairan, drainase, bangunan gedung dan fasilitas publik lainnya, yang dibutuhkan untuk memenuhi kebutuhan dasar manusia baik kebutuhan sosial maupun kebutuhan ekonomi. Pengertian ini merujuk pada infrastruktur sebagai suatu sistem. Dimana infrastruktur dalam sebuah sistem adalah bagian-bagian berupa sarana dan prasarana (jaringan) yang tidak terpisahkan satu sama lain.

Jalan dikelompokkan dalam beberapa kelas berdasarkan muatan sumbu yang ditetapkan berdasarkan fungsi dan intensitas Lalu Lintas guna kepentingan pengaturan penggunaan Jalan dan Kelancaran Lalu Lintas dan Angkutan Jalan; dan daya dukung untuk menerima muatan sumbu terberat dan dimensi Kendaraan Bermotor. 
Jalan umum menurut fungsinya berdasarkan pasal 8 Undang-undang No 38 tahun 2004 tentang Jalan dikelompokkan ke dalam jalan arteri, jalan kolektor, jalan lokal, dan jalan lingkungan: (a)

Jalan arteri merupakan jalan umum yang berfungsi melayani angkutan utama dengan ciri perjalanan jarak jauh, kecepatan rata-rata tinggi, dan jumlah jalan masuk dibatasi secara berdaya guna,(b)jalan kolektor merupakan jalan umum yang berfungsi melayani angkutan pengumpul atau pembagi dengan ciri perjalanan jarak sedang, kecepatan rata-rata sedang, dan jumlah jalan masuk dibatasi, (c) jalan lokal merupakan jalan umum yang berfungsi melayani angkutan setempat dengan ciri perjalanan jarak dekat, kecepatan rata-rata rendah, dan jumlah jalan masuk tidak dibatasi, (d)jalan lingkungan merupakan jalan umum yang berfungsi melayani angkutan lingkungan dengan ciri perjalanan jarak dekat, dan kecepatan rata-rata rendah.

Jalan pedestrian merupakan elemen pendukung bagi kenyamanan bagi kenyamanan aktivitas dan kehidupan ruangruang kota. Jarak tempuh pejalan kaki menurut Uterman (1984) masih dianggap menyenangkan sampai dengan jarak 500 yard (455m).sedangkan menurut Charlthop dalam Child (1999) kenyamanan berjalan kaki masih dapat dirasakan sampai jarak $600 \mathrm{~m}$, meskipun untuk orang berbelanja dapat berjalan sampai 2 jam dengan jarak sampai 2 mil tanpa disadari sepenuhnya oleh pelaku.

Jarak Minimum Jalur Pejalan Kaki dengan Bangunan, jaringan pejalan kaki di perkotaan dapat berfungsi untuk berbagai tujuan yang beragam. Gambar 1 menunjukkan bahwa secara umum ruas pejalan kaki di depan gedung terdiri dari jalur bagian depan gedung, jalur pejalan kaki, dan jalur perabot jalan.Jaringan pejalan kaki memiliki perbedaan ketinggian baik dengan jalur kendaraan bermotor ataupun dengan jalur perabot jalan. Perbedaan tinggi maksimal antara jalur pejalan kaki dan jalur kendaraan bermotor adalah 0,2 meter, sementara perbedaan ketinggian dengan jalur hijau 0,15 meter (Peraturan

\section{Menteri Pekerjaan Umum Nomor : 03/PRT/M/2014)}

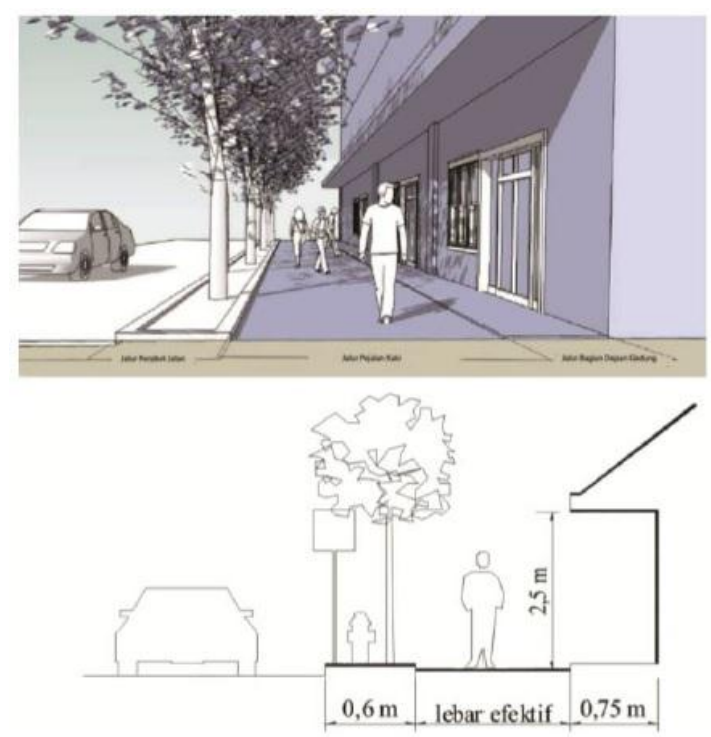

Gambar 1 Kebutuhan Jaringan Pejalan kaki

\section{STUDI KASUS}

\section{Kondisi Ekisting Jaringan Jalan di Koridor Jalan Legian, Kuta}

Jalan Legian adalah jalan utama yang menghubungkan Kuta dengan Seminyak di Bali. Panjang ruas jalan ini sekitar 1,5 kilometer dengan dipenuhi berbagai toko, bar, hotel, dan club. Karena banyaknya hiburan malam dan letaknya yang dekat dengan Pantai Kuta, membuat Jalan Legian menjadi salah satu tujuan wisata yang populer di antara wisatawan di Bali.Jalan Legian sering disalah artikan dengan Legian.Padahal sebenarnya Jalan Legian adalah penghubung antara daerah Kuta dengan Legian. Sehingga Jalan Legian sebenarnya berarti penghubung ke Desa Legian, bukan keseluruhan wilayah Legian itu sendiri.( www.wikipedia.com) 


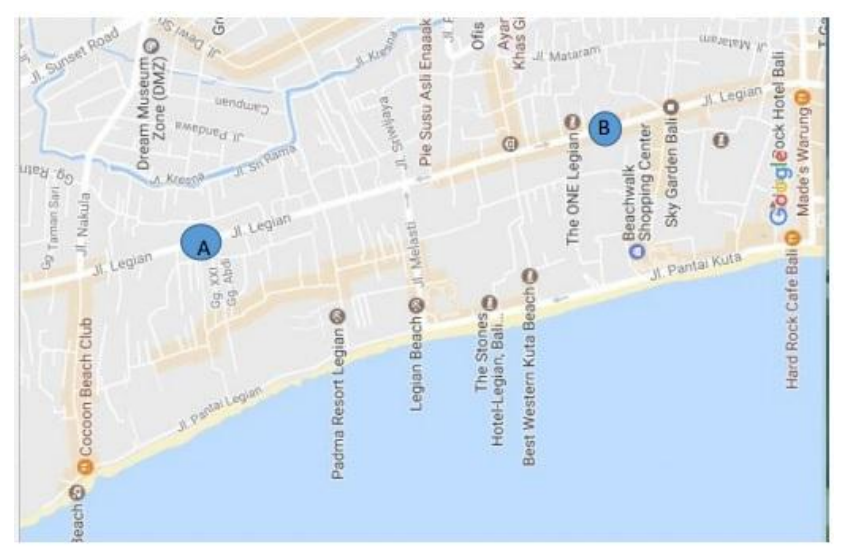

Gambar 2.Peta Jaringan Jalan Legian, Kuta

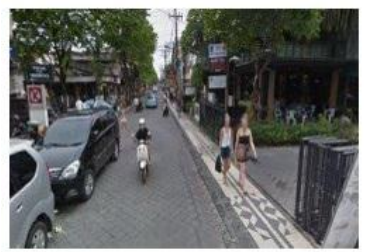

(a) merupakan gambar kondis jaringan jalan di koridor jalan Legian

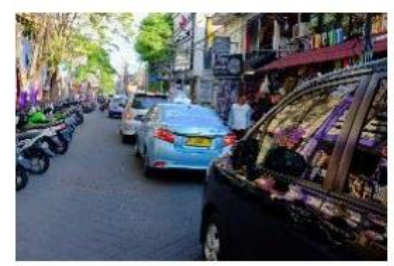

(b) merupakan gambar kondisi jaringan jalan di koridor jalan Legian

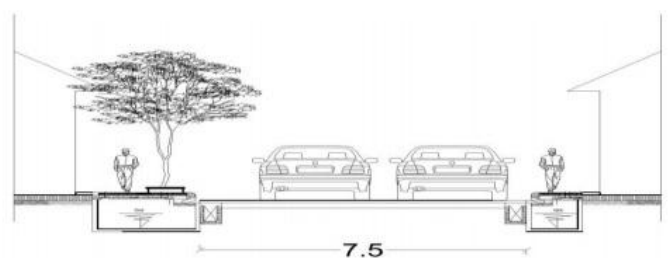

Gambar 3. Kondisi Jaringan Jalan Legian, Kuta

\section{Kondisi Ekisting Ruang Pejalan Kaki di Koridor Jalan Legian, Kuta}

Sistem ruang pejalan kaki di koridor jalan Legian memiliki dua ruangpejalan kaki dengan perbedaan dimensi pada bagian ruas kanan dan kiri jalan.Bahan perkerasan ruang pejalan kaki di lokasi ini menggunakan bahan granit tiledengan warna dasar krem dan sedikit berwarna hitam pada bagian tengah danpinggir ruang pejalan kaki dengan dimensi ukuran pada ruas kiri pejalan kakiyaitu 2,5 meter dan pada ruas kanan pejalan kaki memiliki dimensi 1,3 meterdengan ketinggian ruang pejalan kaki sekitar $10 \mathrm{~cm}$.

Berdasarkan pengamatansecara langsung terdapat beberapa permasalahan terkait ruang pejalan kaki yangterjadi di sepanjang koridor jalan Legian yaitu kurang memadainya kelengkapansarana ruang pejalan kaki seperti: lampu penerangan, tempat duduk, tempat sampah dan jalur penyandang disabilitas.

Selain itu, alih fungsi ruang pejalan kaki juga memberikan dampak terganggunya kenyamanan pejalan kaki akibat berkurangnya ruang pejalan kaki dan rendahnya tingkat kesadaran terhadap pemeliharaan ruang pejalan kaki yang digunakan tidak sesuai fungsinya juga memberikan dampak kerusakan ruang pejalan kaki.

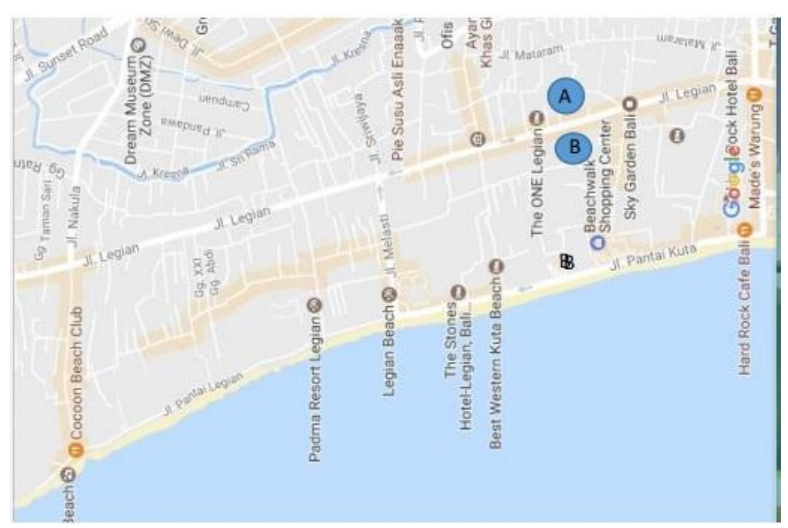

Gambar 4. Peta Kondisi Ruang Pejalan Kakidi Jalan Legian, Kuta
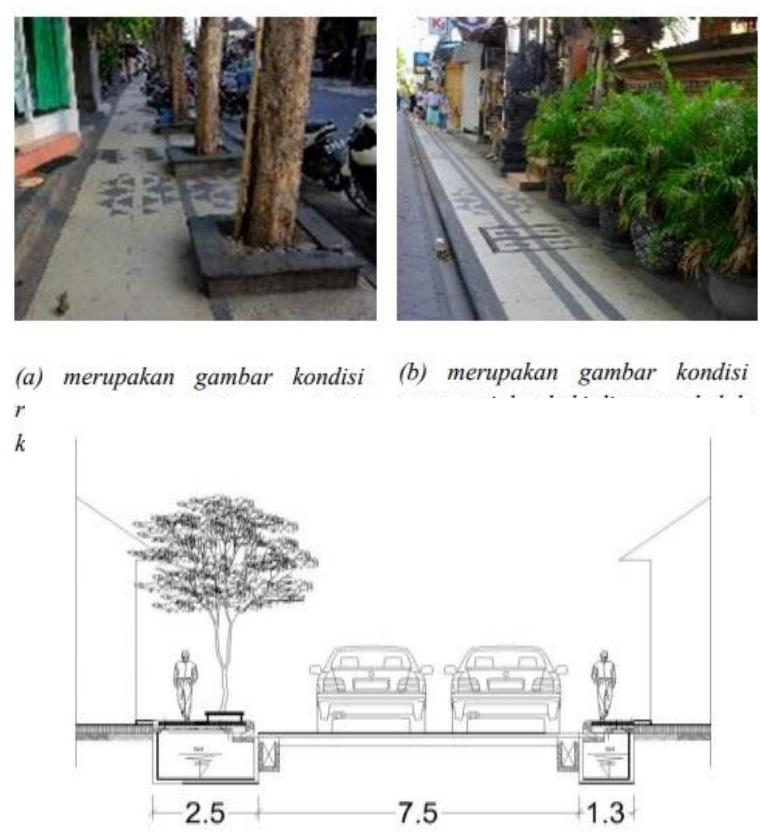

Gambar 5. Kondisi Ruang Pejalan Kaki di Jalan Legian, Kuta 


\section{Analisis Kebijakan Pembangunan Infrastruktur Jaringan Jalan di Koridor Jalan Legian, Kuta}

Berdasarkan klasifikasi jalan menurut Peraturan Daerah Kabupaten Badung Nomor 26 Tahun 2013 Tentang Rencana Tata Ruang Wilayah Kabupaten Badung Tahun 2013 2033, jalan lokal primer didesain berdasarkan kecepatan rencana paling rendah $20 \mathrm{~km} / \mathrm{jam}$ (dua puluh kilometer per jam) dengan lebar badan jalan paling sedikit 7,5 m (tujuh koma lima meter).

Dalam hal ini jalan Legian termasuk dalam jalan lokal primer dengan lebar jalan sekitar 7, 5 meter. Berdasarkan hasil pengamatan langsung di koridor jalan Legian, klasifikasi jaringan jalan sudah sesuai dengan RTRW Kabupaten Badung dan juga terihat dari minimnya jalan rusak yang terdapat di koridor jalan Legian ini.

Terkait penanganan permasalahan kurang memadainya sarana penerangan jalan, solusinya yaitu dengan penyediaan saran penerangan jalan karena berkaitan dengan keselamatan para pengguna jalan. Selain itu, kemacetan yang sering terjadi akibat banyaknya volume kendaraan dan kendaraan taksi yang berhenti secara sembarangan,solusinya yaitu dengan lebih meningkatkan pengawasan dalam arus lalu lintas dan memberikan sanksi untuk memberikan efek jera terhadap kendaraan yang melanggar.

Pengangan masalah kurang tersedianya prasarana seperti zebra cross atau area penyeberangan bagi pejalan kaki, solusinya yaitu penyediaan sarana penyeberangan jalan di beberapa titik sehingga para pejalan kaki yang ingin menyebarang tidak meyebrang secara sembarangan yang dapat menganggu arus lalu lintas dan membahayakan keselamatan baik pengendara ataupun pejalan kaki.

\section{Analisis Kebijakan Pembangunan Infrastruktur Ruang Pejalan Kaki di Koridor Jalan Legian, Kuta}

Berdasarkan Peraturan Daerah Kabupaten Badung Nomor 26 Tahun 2013 Tentang Rencana Tata Ruang Wilayah Kabupaten Badung tidak disebutkan bahan perkerasan ruang pejalan kaki di lokasi ini menggunakan bahan granit tile sehingga perlu direvisi lagi sehingga memiliki kekuatan hukum, pengadaan pemavingan pada ruas jalan dan perbaikan ruang pejalan kaki menggunakan bahan grait tile merupakan upaya pemerintah dalam beautifikasi di koridor jalan Legian ini. Menurut surat kabar online Antara News Bali tanggal 29 Agustus Tahun 2010 menjelaskan proyek beautifikasi ini ingin mengadopsi konsep pedestrian di Frankfurt Square, Jerman sehingga dengan penataan tersebut diharapkan dapat menjadi kawasan yang nyaman bagi pejalan kaki.yang terdapat di koridor jalan Legian hanya jalur hijau itupun hanya berada di satu sisi ruas kanan pejalan kaki, sehingga kelengkapan sarana ruang pejalan kaki masih rendah di koridor jalan Legian ini.

Terkait penanganan permasalahan ketersediaan kelengkapan sarana ruang pejalan kaki seperti: lampu penerangan, tempat duduk, tempat sampah dan jalur penyandang disabilitas, solusinya yaitu penyediaan sarana dan prasarana ruang pejalan kaki karena kelengkapan fasilitas tersebut menunjang kenyamanan dan keselamatan para pejalan kaki.

Selain itu, penanganan permasalahan alih fungsi ruang pejalan kaki, solusinya yaitu dengan membuat aturan tentang penertiban parkir di ruang pejalan kaki dan menyiapkan titik-titik kantong parkir.Penganganan permasalahan rendahnya tingkat kesadaran terhadap pemeliharaan ruang pejalan kaki, solusinya yaitu dengan memberikan sosialisasi kepada pengguna atau pegawai toko di ruas koridor jalan Legian agar lebih memerhatikan lingkungan sekitar.

Berdasarkan Peraturan Menteri Pekerjaan Umum Nomor: 03/PRT/M/2014 / Tentang Pedoman Perencanaan, Penyediaan, Dan Pemanfaatan Prasarana Dan Sarana Jaringan Pejalan Kaki Di Kawasan Perkotaan. Pada peraturan ini mendeskripsikan perhitungan dimensi tubuh manusia, 
kebutuhan ruang minimum pejalan kaki: (a) tanpa membawa barang dan keadaan diam yaitu $0,27 \mathrm{~m} 2$; (b) tanpa membawa barang dan keadaan bergerak yaitu $1,08 \mathrm{~m} 2$; dan (c) membawa barang dan keadaan bergerak yaitu antara 1,35 m2 -1,62 m2.

Berdasarkan hasil pengamatan langsung di koridor jalan Legian, dimensi ruang pejalan kaki sudah sesuai dengan aturan standar nasional tersebut yaitu : berukuran 2,5 meter padaruas sebelah kanan pejalan kaki dan pada ruas sebelah kiri berukuran 1,3 meter. Namun pada Peraturan Daerah Kabupaten Badung Nomor 26 Tahun 2013 Tentang Rencana Tata Ruang Wilayah Kabupaten Badung tidak disebutkan untuk aturan standar ruang pejalan kaki.

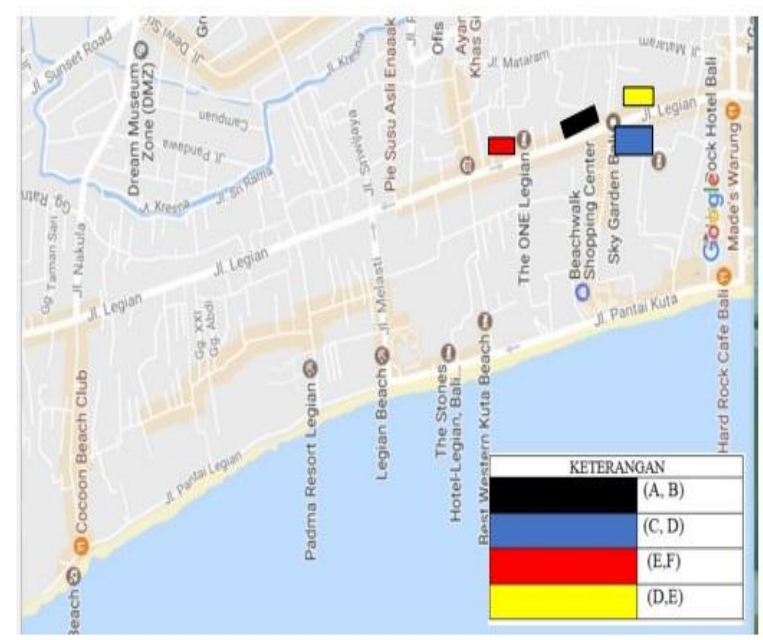

Gambar 6. Kondisi Fisik Perumahan

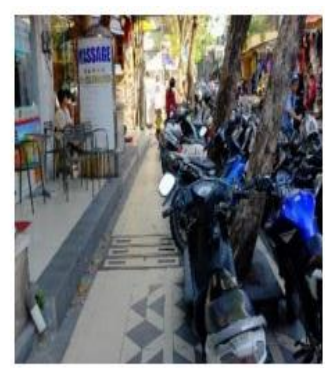

(a) merupakan gambar alih fungsi pada ruang pejalan kaki di koridor jalan Legian yang digunakan sebagai tempat parkir sehingga mengurangi ruang gerak bag pejalan kaki

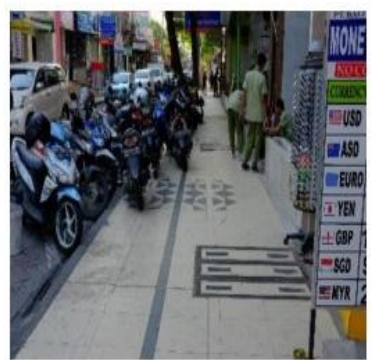

(b) merupakan gambar alih fungsi pada ruang pejalan kaki di koridor jalan Legian yang digunakan sebagai tempat parkir dan sebagai tempat memajang stand toko sehingga menganggu kenyamanan pejalan kaki

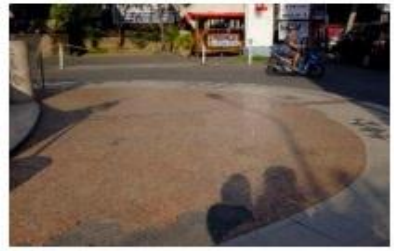

(c) merupakan gambar kerusakan (d)

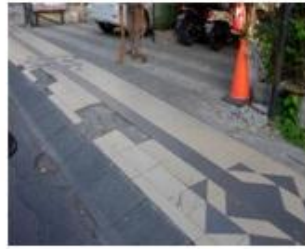
muang pejalan kaki di monument granit tile pada ruang pejalon Ground Zero, jalan Legian. kaki di koridor jalan Legian.

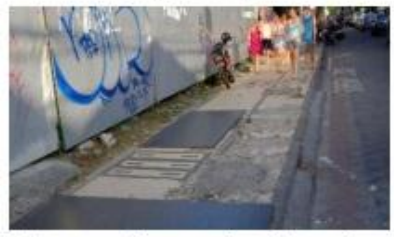

(e) merupakan gambar kerusakan bahan perkerasan granit tile pada ruang pejalan kaki di koridor jalan Legian yang disebabkan alih fungsi pedestrian seperti penggunaan tempat parkir

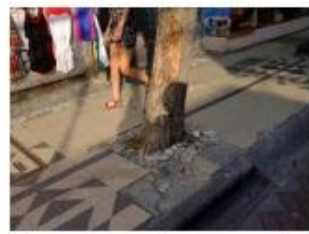

(f) merupakan gamba kerusakan bahan perkerasan granit tile pada ruang pejalan kaki di koridor jalan Legian yang disebabkan tidak adanya planter box sehingga akar pohon merusak bahan perkerasan
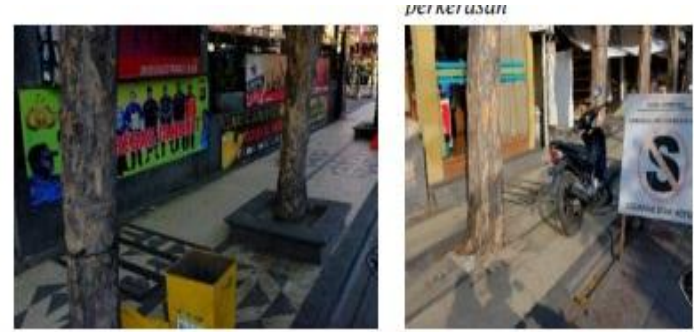

(g) merupakan gambar tingkat kebersihan pada (h) merupakan gambar alih ruang pejalan kaki di koridor jalan Legian yang fungsi ruang pejalan kaki di disebabkan tingkat kesadaran masyarakat yang koridor jalan Legian rendah terhadap pemeliharaan ruang pejalan kaki

Gambar 7. Kondisi Analisis Ruang Pejalan Kaki di Jalan Legian, Kuta

\section{KESIMPULAN}

Sistem jaringan jalan Legian merupakan jalan satu arah dengan bahan perkerasan jalan didominasi menggunakan bahan paving. Dalam hal ini jalan Legian termasuk dalam jalan lokal primer dengan lebar jalan sekitar 7, 5 meter. Sistem ruang pejalan kaki di koridor jalan Legian memiliki dua ruang pejalan kaki dengan perbedaan dimensi pada bagian ruas kanan dan kiri jalan. Bahan perkerasan ruang pejalan kaki di lokasi ini menggunakan bahan granit tile dengan 
warna dasar krem dan sedikit berwarna hitam pada bagian tengah dan pinggir ruang pejalan kaki dengan dimensi ukuran pada ruas kiri pejalan kaki yaitu 2,5 meter dan pada ruas kanan pejalan kaki memiliki dimensi 1,3 meter dengan ketinggian ruang pejalan kaki sekitar $10 \mathrm{~cm}$.

Terkait penanganan permasalahan kurang memadainya sarana penerangan jalan, solusinya yaitu dengan penyediaan saran penerangan jalan karena berkaitan dengan keselamatan para pengguna jalan. Selain itu, kemacetan yang sering terjadi akibat banyaknya volume kendaraan dan kendaraan taksi yang berhenti secara sembarangan,solusinya yaitu dengan lebih meningkatkan pengawasan dalam arus lalu lintas dan memberikan sanksi untuk memberikan efek jera terhadap kendaraan yang melanggar. Penanganan masalah kurang tersedianya prasarana seperti zebra cross atau area penyeberangan bagi pejalan kaki, solusinya yaitu penyediaan sarana penyeberangan jalan di beberapa titik sehingga para pejalan kaki yang ingin menyebarang tidak meyebrang secara sembarangan yang dapat menganggu arus lalu lintas dan membahayakan keselamatan baik pengendara ataupun pejalan kaki.

Terkait penanganan permasalahan ketersediaan kelengkapan sarana ruang pejalan kaki seperti: lampu penerangan, tempat duduk, tempat sampah dan jalur penyandang disabilitas, solusinya yaitu penyediaan sarana dan prasarana ruang pejalan kaki karena kelengkapan fasilitas tersebut menunjang kenyamanan dan keselamatan para pejalan kaki. Selain itu, penanganan permasalahan alih fungsi ruang pejalan kaki, solusinya yaitu dengan membuat aturan tentang penertiban parkir di ruang pejalan kaki dan menyiapkan titik-titik kantong parkir.Penganganan permasalahan rendahnya tingkat kesadaran terhadap pemeliharaan ruang pejalan kaki, solusinya yaitu dengan memberikan sosialisasi kepada pengguna atau pegawai toko di ruas koridor jalan Legian agar lebih memerhatikan lingkungan sekitar.

\section{DAFTAR PUSTAKA}

Shirvani, Hamid. 1996. The Urban Design Process. VNR Company Inc. New York

Spreiregen, Paul D. 1965. Urban Design Process: The Architecture of Towns and Cities, McGraw-Hill Book Company.

Zahnd, Markus 1999. Perancangan Kota Secara Terpadu.Kanisius. Yogyakarta

Pedoman Konstruksi dan Bangunan Nomor 8 Tahun 2000 Tentang Penentuan Klasifikasi Fungsi Jalan dan Kawasan

Peraturan Daerah Kabupaten Badung Nomor 26 Tahun 2013 Tentang Rencana Tata Ruang Wilayah Kabupaten Badung Tahun 2013 - 2033

Peraturan Menteri Pekerjaan Umum Nomor :03/PRT/M/2014/Tentang Pedoman Perencanaan, Penyediaan, Dan Pemanfaatan Prasarana Dan Sarana Jaringan Pejalan Kaki Di Kawasan Perkotaan 